Editorial Board. Publication from cameraready manuscripts appears to offer rapid publication, but no dates of receipt are given on the articles.

This journal in no way competes with the Royal Society of Chemistry's Annual Reports on Analytical Atomic Spectroscopy which are devoted to fairly comprehensive reviews of all activity in the field during the previous year. Instead, PAAS gives in-depth treatment to small areas or specific topics, or critical surveys of the application of these techniques to specific industries, for example nuclear energy materials, cement, refractories, paints, soils and plants. The juxtaposition of reviews on various industrial analyses and others of a fundamental academic nature is at first a little disconcerting, but it does perhaps substantiate the observation that the field is one which is expanding rapidly.

I cannot honestly say that this journal fulfills the same unique role as JAC, since quite a few of its articles might equally well be found elsewhere and there is consequently no characteristic "flavour" to the journal. But what PAAS does outstandingly well is to offer the opportunity for publication of uniquely long and detailed fundamental papers, and if this aspect can be further developed the journal will undoubtedly attain a character of its own and serve a vital role.

T.S. West is Director of The Macaulay Institute for Soil Research, Craigiebuckler, Aberdeen, and was formerly Professor of Analytical Chemistry at Imperial College, University of London.

\title{
Inorganic Chemistry for the Broad-minded
}

\section{J.A. McCleverty}

Reviews in Inorganic Chemistry. Editors H.D.B. Jenkins and D.F.C. Morris. 4/yr. (Freund, Tel Aviv, Israel/Wiley.) \$85.

IN THEIR preface, the editors of Reviews in Inorganic Chemistry (RIC) make a point of inviting short, authoritative articles which will be seen as personal reviews of the author's own research set in the context of other work in the field. Larger and more broadly based reviews are also solicited, and in recent issues book reviews are included.

Thus the policy of the journal is to encourage new insights and to promote interest and research activity across the span of inorganic chemistry. The editors apparently hope to achieve this by placing no restrictions on what constitutes inorganic chemistry in order to promote the interplay of ideas between subdivisions of the subject. Certainly, a wide variety of topics have been reviewed to date, ranging from basic coordination chemistry, through thermodynamics, spectroscopy, electrochemistry and chromatography, to solid-state chemistry.

There are short personal accounts and longer more general contributions of variable quality, but some useful articles by well-known chemists have also appeared. The delay between receipt of manuscripts and their appearance has apparently decreased since the first issue, and seems reasonable. Thus the editors appear to be achieving some of their aims, one of which

\section{Transitions in Solid-state Physics}

\section{Roger Pynn}

Phase Transitions. Editors-in-chief A.M. Glazer and R. Smoluchowski. 4/yr. (Gordon \& Breach.) 1981: \$107.

THE avowed aim of Phase Transitions (PT) is to provide "a focus for papers on most aspects of phase transitions in condensed matter'. Yet it is not obvious that such a focus is necessary or even desirable. During the past decade of expanding interest in phase transitions, the established condensed-matter journals have provided an adequate forum for papers on phase transitions and have maintained a measure of contact between students of this sub-discipline and the remainder of the solid-state physics community.

Although papers published to date in this new journal have been of a quality which is above average, none can be described as seminal. The editors have tried to improve the refereeing system by keeping authors' names and affiliations from the referees, an interesting idea which could be adopted profitably elsewhere; some established journals of ten appear to give undue prominence to a limited number of laboratories. Although fair, the refereeing is often not particularly rapid overall, the delay between the submission of a paper and its appearance varies between six months and more than a year. This situation is exacerbated by the relatively infrequent publication schedule (about four issues per year).

The quality of production of the journal is excellent and the lack of page charges and of length limitation seems to have encouraged papers which are selfcontained and well expounded. However, to flourish beyond its infancy PT must attract, in addition, a few landmark contributions and establish a reputation in this specific area of study.

Roger Pvnn is at the Institut Laue-Langevin, Grenoble. is rapid publication.

It seems unlikely that individuals would buy RIC, but departments having a broad range of inorganic interests might. The price is not excessive and the quality of production quite satisfactory. However, in my opinion the journal does not fill an obvious gap; rather, I would guess that it tends to siphon off articles from more specialized review periodicals. I would place it in the middle rank of quality, certainly below its Wiley stablemate, Progress in Inorganic Chemistry.

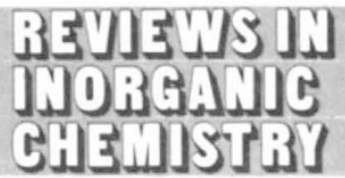

RIC, then, is not without worth. But a warning note is sounded by the fact that although it was launched in January 1979 with a quarterly publication schedule, only eight issues have appeared to date.

J.A. McCleverty is Professor of Inorganic Chemistry at the University of Birmingham.

\section{Disposal Technology}

\section{R.I. Newman}

Nuclear and Chemical Waste Management. Editors-in-chief L. Cranberg and A.A. Moghissi. 4/yr. (Pergamon.) $\$ 80$. Radioactive Waste Management. Editorin-chief D.R. Anderson. 4/yr. (Harwood.) Dfl.150, \$55. European Applied Research Reports: Nuclear Science and Technology Section. Irregular. (Harwood.) Dfl.855, $\$ 310$ per volume of 1,500 to 1,600 pages.

TIIE appearance of three new journals dealing with the management of radioactive waste, at least in part, is something of an occasion. Among the criteria for the success of a new journal is that it should fill a gap, and there is certainly a need for a forum for the objective discussion of waste management problems. Thus I took up with optimism the task of reading the 40 or so papers and the accompanying editorial statements in the first four issues of each of these journals.

The statement of editorial policy in Radioactive Waste Management (RWM) is entirely to my liking. I applaud the editors' intentions to be "skeptical of submissions that continue to press for a 'best' instead of acceptable solution(s) to technical, political or social problems". And it is good that Nuclear and Chemical Waste Management (NCWM) quotes from a statement by the Coordinating Committee on Energy to the effect that "Nuclear waste 